\title{
Antifungal activity of methanolic and ethanolic leaf extracts of medicinal plants
}

HARIOM KUMAR SINGH, INDRA PRAKASH, VARUN KUMAR, SAURABH GUPTA AND AMIT ALEXANDER CHARAN*

Department of Molecular and Cellular Engineering, Jacob School of Biotechnology and Bioengineering, Sam Higginbottom Institute of Agriculture, Technology and Sciences, ALLAHABAD (U.P.) INDIA

\section{ARITCLE INFO \\ Received : 28.04 .2016 \\ Revised : 20.08.2016 \\ Accepted : 04.09.2016}

KEY WORDS :

Antifungal, Methanolic leaf extracts, Ethanolic leaf extracts

*Corresponding author:

Email : amit.charan@shiats.edu.in

\begin{abstract}
The following plants were screened for thew study viz., Ocimum sanctum (Tulsi), Withania somnifera (Ashwagandha) and Asparagus racemosus (Shatavari) which were traditionally used in India to treat various diseases. In evaluating antioxidant property and phytochemical analysis, all three plants were screened for antifungal activity. It was evaluated using Well diffusion method. The extracts were tested against fungus Aspergillus niger. Inhibition of fungal growth was investigated using PDA well diffusion method. The contents of total flavonoid compounds in crude methanolic and ethanolic extracts obtained from Ocimum sanctum, Withania somnifera and Asparagus racemosus leaves.
\end{abstract}

How to view point the article : Singh, Hariom Kumar, Prakash, Indra, Kumar, Varun, Gupta, Saurabh and Charan, Amit Alexander (2016). Antifungal activity of methanolic and ethanolic leaf extracts of medicinal plants. Internat. J. Plant Protec., 9(2) : 474-478, DOI : 10.15740/HAS/ IJPP/9.2/474-478. 